\title{
El activismo social y político de las mujeres durante la República de Cuba (1902- 1959) ${ }^{1}$
}

\author{
Manuel Ramírez Chicharro²
}

Resumen: Durante el primer tercio del siglo XX, el movimiento feminista en Cuba concentró sus esfuerzos en promover algunas reformas civiles y en la conseguir que se aprobase el sufragio femenino. Ambas medidas venían a cuestionar el rol de la Iglesia y el Estado en lo concerniente a la estructuración social y la moralidad de la ciudadanía. La Constitución de 1940 incorporó las medidas aprobadas durante las primeras décadas de la república y delimitó un marco jurídico más favorable para el desarrollo profesional de las mujeres en el ámbito público. Asimismo, permitió a nivel teórico la participación femenina en el sector político. Sin embargo, las estadísticas demuestran que las mujeres cubanas, en especial las mujeres afrocubanas, quedaron al margen de las principales instituciones estatales. De ahí su inclinación a integrar asociaciones socio-políticas, a través de las cuales canalizaron su interés por cambiar su entorno más cercano mediante la demanda de mejoras en el sistema educativo o la seguridad social. En el ejercicio del activismo, las mujeres asumieron responsabilidades colectivas y ganaron experiencia en la gestión de problemas nacionales a pequeña escala. Su compromiso con la implementación y el desarrollo de la legislación más democrática que había tenido Cuba generó un sentimiento de adhesión a las libertades políticas que las empujó a integrar la oposición al gobierno de Fulgencio Batista tras el golpe de Estado de 1952.

Palabras-claves: Cuba, siglo XX; Periodo republicano; historia de las mujeres; movimiento feminista; activismo socio-político

\section{The social and political activism of women in the Republic of Cuba (1902-1959)}

Abstract: During the first third of the XX century, the feminist movement in Cuba concentrated its effort to promote some civic reforms and the women's right to vote to be enacted by parliamentarians. Both measures came to challenge the role of Church and State concerning the social structure and the morality of the Cuban citizenship. The approval of the 1940 Constitution incorporated the legislative changes passed during the first decades of the Republic

\footnotetext{
${ }^{1}$ La elaboración de este artículo se enmarca en el proyecto de investigación "El espacio antillano: génesis, circulación y redistribución de individuos, mercancías, ideas, saberes y modelos (siglos XVIII-XXI)" (HAR201566152-R), dirigido por la Dra. Consuelo Naranjo Orovio en el Instituto de Historia del CSIC, y la beca predoctoral Formación Profesorado Universitario (FPU 12/06945) del Ministerio de Educación, Cultura y Deporte de España adscrita al CSIC y al Programa de Doctorado de la Universidad de Castilla-La Mancha.

${ }^{2}$ Graduado en Historia por la Universidad de Castilla-La Mancha (UCLM, 2006-2010). Máster en Formación del Profesorado de Educación Secundaria (UCLM, 2011) y Máster en Investigación de Letras y Humanidades, mención en Historia (UCLM, 2012). La elaboración de este artículo se enmarca en el proyecto de investigación "El espacio antillano: génesis, circulación y redistribución de individuos, mercancías, ideas, saberes y modelos (siglos XVIII-XXI)" (HAR2015-66152-R), dirigido por la Dra. Consuelo Naranjo Orovio en el Instituto de Historia del CSIC, y la beca predoctoral Formación Profesorado Universitario (FPU 12/06945) del Ministerio de Educación, Cultura y Deporte de España adscrita al CSIC y al Programa de Doctorado de la Universidad de Castilla-La Mancha.
}

\section{GANPHLAC}

Revista Eletrônica da ANPHLAC, ISSN 1679-1061, No. 20, p. 141-172, Jan/Jun., 2016.

http://revista.anphlac.org.br 
period and set a more suitable juridical framework to develop their own professional careers in the public space. Although it theoretically allowed women's participation in the political sector, statistics demonstrate that Cuban women, especially afro-Cuban ones, were pushed to the sidelines by main statistic institutions. Hence their propensity to enroll socio-political associations, through where they channeled their desires to enhance their immediate environment by demanding improvements in the education or health-care system. In the exercise of the activism, Cuban women took more collective responsibilities and got experience to handle small-scale national problems. Their commitment to implement and develop the most democratic legislation Cuba had ever had led to a sense of belonging to political freedoms. Ultimately, the Coup d'Etat by Fulgencio Batista in 1952 led them to integrate the political opposition to his government.

Keywords: Cuba, XX century, Republic period, Women history, Feminist movements, sociopolitic activism

Artigo recebido em: 18/02/16

Artigo aprovado para publicação em: 10/05/2016

\section{Introducción}

Las reformas del gobierno revolucionario cubano dirigidas a mejorar la situación de las mujeres cubanas han facilitado, en gran medida, la integración laboral y la equiparación de los derechos civiles y políticos de los cubanos y las cubanas. La creación de la Federación de Mujeres Cubanas como órgano de expresión y participación femenina en 1961, la implementación del código de la familia de 1975 y de diferentes medidas laborales y asistenciales reconocieron los nuevos derechos y deberes de las mujeres cubanas dentro del nuevo estado. Sin embargo, con el afán de destacar los logros de la revolución, se han infravalorado las movilizaciones y los avances obtenidos por las mujeres en pro de la igualdad legislativa y la integración social durante los años de la República anterior a 1959.

El análisis del periodo republicano permite apreciar el sentido reformista e innovador de gran parte de las iniciativas que promovieron estos grupos de mujeres. ${ }^{3}$ Las propuestas de estas organizaciones y su membresía han sido interpretadas desde la óptica marxista como el

\footnotetext{
${ }^{3}$ El análisis de las revistas Verde Olivo, Mujeres y Bohemia entre los años 1959-1980 apenas arroja una decena de artículos relativos a demandas realizadas o reformas implementadas obtenidos por las asociaciones femeninas durante el periodo republicano.
}

\section{GANPHLAC}

Revista Eletrônica da ANPHLAC, ISSN 1679-1061, №. 20, p. 141-172, Jan/Jun., 2016. 
precedente burgués de la verdadera emancipación femenina que llegaría con la instauración del sistema comunista que aboliese las diferencias de clase, y en consecuencia los privilegios de género y las discriminaciones raciales, a pesar de que algunas autoras han apuntado las múltiples diferencias e incluso contradicciones entre marxismo y feminismo (MACKINNON, 1983, p. 635-658). Sin embargo, es imposible comprender este proceso sin analizar la etapa previa a la luz del contexto internacional de la primera mitad del siglo XX, que sembró en todo el continente americano el precedente para los cambios más profundos que llegarían durante la segunda ola feminista entre 1960 y 1980.

Varias investigaciones han abordado tanto el asociacionismo en Cuba como las reformas que las diferentes agrupaciones trataron de realizar. En algunos casos se ha tratado de confeccionar un relato pormenorizado de los acontecimientos, los grupos y sus principales dirigentes (PAGÉS, 2003; STONNER, 2003, p. 297), mientras que en otras ocasiones las autoras han llevado a cabo análisis ideológicos a partir de los programas de las principales asociaciones, pero también de las obras líricas de algunas de sus integrantes (MULHARE, 1969; JOHNG, 1995, p. 3-12; DAVIES, 1996, p. 107-123; MENÉNDEZ, 1993; CHASE, 2015). Son escasos los estudios sobre asociaciones específicas conformadas únicamente por mujeres que lucharon por mejorar su situación u otras enfocadas a la subversión del sistema político (REXACH, 1986; MONTEJO, 1998, p. 33-48; CASTRO PORTA, 2010). Existen algunos estudios biográficos que profundizan en las líderes más destacadas del movimiento feminista en Cuba durante la primera mitad del siglo XX (CRUZ MARTÍNEZ, 1990; GUERRERO, 1991; MARTÍNEZ MALO, 2010). Hasta la fecha, solo algunas investigaciones han tratado de forma específica la problemática racial dentro del movimiento feminista en Cuba, así como el activismo cívico y político que llevaron a cabo las mujeres afrodescendientes (RUBIERA CASTILLO, 2000; LYNETTE LOGAN, 2010, p. 5-39; ARVEY, 2010, p. 627 659; KEOSHA, 2011; ORTIZ-LOYOLA, 2013; RAMÍREZ CHICHARRO, 2015).

En este trabajo se entiende por "asociaciones sufragistas" aquellas organizaciones que encaminaron sus demandas a conseguir que el derecho al voto se hiciese extensivo a las mujeres. Las "asociaciones feministas" eran las agrupaciones que, contemplando o no el sufragio como reforma necesaria, defendían un programa de reivindicaciones más amplias, relativas al entorno laboral, el código civil y las relaciones de género en el ámbito privado. Las "asociaciones femeninas" eran las organizaciones integradas únicamente por mujeres que,

\section{GANPHLAC}

Revista Eletrônica da ANPHLAC, ISSN 1679-1061, №. 20, p. 141-172, Jan/Jun., 2016. 
promoviendo o no campañas en favor de los derechos de las mujeres, desempeñaban además acciones políticas o sociales de carácter nacional o internacional. Por otro lado, se define "acción política" o "activismo social" como toda aquella iniciativa encaminada a cambiar, por la vía reformista o revolucionaria, el equilibrio de poderes a nivel legal e institucional con el objetivo de mejorar la situación individual, la de un sector social o la del conjunto de la ciudadanía. Este tipo de actuaciones pueden perseguir el cambio de leyes, decretos o estatutos de toda índole, pero también proporcionar ayuda a sectores sociales más desfavorecidos ante la falta de iniciativa de las instituciones estatales. En el caso de Cuba, las mujeres conformaron asociaciones tanto de carácter cívico como político. Si bien el sufragismo es un claro ejemplo de acción política, las campañas con carácter benéfico y filantrópico también pueden ser encuadradas dentro del activismo social porque constituían, en sí mismas, una forma de denuncia y reivindicación. Por medio de sus actividades no solo contribuyeron a mejorar la situación de las mujeres de su entorno, sino a visibilizar determinadas problemáticas. El asociacionismo permitió a las mujeres transitar progresivamente desde el espacio privado hacia el espacio público y movilizaron a gran parte de la sociedad civil que no participaba de las instituciones estatales o partidos políticos. Esta cadena de acciones, en conjunto, reforzó el compromiso de las mujeres cubanas con los problemas nacionales e introdujo un cambio de conciencia en parte de la ciudadanía respecto a la capacidad que las mujeres tenían para proponer medidas, gestionar recursos y desempeñar acciones. Cuando el golpe de Estado de 1952 suspendió el régimen constitucional que estas mujeres habían contribuido a desarrollar y expandir, algunas asociaciones de carácter benéfico y asistencial comenzaron a emprender acciones políticas contra la dictadura de Fulgencio Batista.

\section{La primera ola feminista en Cuba: igualdad política y reconocimiento social}

La República de Cuba nació atravesada por múltiples conflictos raciales, sociales e ideológicos. La persistencia de las estructuras sociales del periodo colonial y el intento por parte de algunos grupos de implantar el nuevo paradigma de la modernización siguiendo el modelo norteamericano generaron una serie de conflictos que impidieron la articulación y cohesión de la ciudadanía cubana a comienzos de la República (RIVERA MARTÍNEZ, 1992; NÚÑ̃E,

\section{GANPHLAC}

Revista Eletrônica da ANPHLAC, ISSN 1679-1061, №. 20, p. 141-172, Jan/Jun., 2016. 
2011, p. 71-249; DESVERNINE REED, 2013, p. 62-123). Las prácticas culturales y sociales racistas y los perjuicios de género impidieron la integración social de las mujeres y de algunas minorías cuya condición de ciudadanía se vio menguada en el nuevo modelo de estado. La asamblea Constituyente de 1901 rechazó por 9 votos a favor y 17 en contra la moción presentada por Miguel Gener, Salvador Cisneros Betancourt y José Lacret para conceder el voto a las mujeres. La nueva carta magna estableció que las mujeres no podrían ser candidatas, ni participar en ninguna clase de comicios, del mismo modo que los menores de edad, los asilados, los incapacitados mental o judicialmente y los miembros de las fuerzas armadas. ${ }^{4}$

Ante la incapacidad de integrarse en partidos políticos, algunas mujeres procedentes del ámbito urbano crearon las primeras asociaciones femeninas entre 1912 y 1914. Próximas a los partidos liberal y conservador, sus principales objetivos no consistían en alterar las bases morales de la sociedad. Como estos políticos, la ideología de las sufragistas tenía un carácter reformista que la profesora Catherine Davies definió como "feminización del nacionalismo cubano". Según la autora, estas primeras mujeres lucharon por concienciar a la ciudadanía y a los políticos de las desigualdades legislativas a las que deberían enfrentarse en el nuevo modelo de Estado, pero sin llegar a cuestionarse ellas mismas los roles tradicionales que desempeñaban, así como tampoco los prejuicios raciales hacia la población afrocubana heredados de la época colonial (DAVIES, 1996, p. 108-111; NARANJO OROVIO, 2001, p. 165-172).

Las mujeres de las Antillas hispanas y británicas tomaron como modelos a seguir, respectivamente, a las sufragistas estadounidenses y británicas de la llamada "primera ola feminista" (KRADITOR, 1981, p. 123-261; BARRITEAU, 1998, p. 186-210; STONNER, 2003, p. 57-83; KROLOKKE; SCOTT, 2005, p. 1-7; PÉREZ GARZÓN, 2011, p. 111-140). Desde comienzo de siglo, pero sobre todo después de la I Guerra Mundial, la posición de las mujeres blancas en los estados liberales ganó reconocimiento político por su activa participación en la retaguardia del conflicto bélico. Desde entonces, las mujeres del mundo anglófono vieron reforzada su posición para solicitar mayores reconocimientos políticos. Las mujeres cubanas asumieron el discurso de sus compañeras norteamericanas desde 1912, pero sobre todo a partir de 1917 al lograr que el sufragio fuera tema de debate habitual en la prensa

\footnotetext{
${ }^{4}$ Como se indica en CUBA. Diario de Sesiones de la Convención Constituyente de la Isla de Cuba. La Habana: 1901. Biblioteca de la Universidad de La Habana (BUH): 283-284 y CUBA, Constitución de la República de Cuba, La Habana: 1901, artículo 38. Disponible en http://biblio.juridicas.unam.mx/libros/5/2138/7.pdf.
}

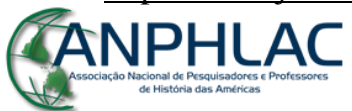

Revista Eletrônica da ANPHLAC, ISSN 1679-1061, №. 20, p. 141-172, Jan/Jun., 2016. 
cubana. Emilia Pérez de Viñas, Digna Collado y Amalia Mallén de Ostolaza, entre otras, lideraron a decenas de mujeres que desde La Habana impulsaron diferentes organizaciones de corto recorrido hasta la creación del Club Femenino de Cuba, en 1918. Sus peticiones abarcaron desde una mayor cobertura legal para las mujeres en el trabajo, a la igualdad de salarios o una nueva Ley de Servicio Civil. Desde su revista oficial, La mujer moderna, el Club Femenino promovió campañas contra la Pena de Muerte, la prostitución, el trabajo infantil e incluso el alcoholismo, una adicción que, junto al maltrato, el abandono o el adulterio, terminó convirtiéndose en un motivo válido y suficiente para solicitar el divorcio en Cuba, una vez la ruptura matrimonial fue incorporada al Código Civil (LAMAR, 1925, p. 25-27; CLUB FEMENINO, 1925, p. 34-35; LAMAR, 1926, p. 27-28; MILLÁS, 1949, p. 270-274).

Entre 1917 y 1918, el Parlamento de Cuba, integrado por hombres en su totalidad, aprobó la Ley de Divorcio y la Ley de Administración de Bienes que algunas autoras interpretan que fue una medida administrativa concerniente a las herencias y propiedades, y no tanto como una consecuencia de las demandas realizadas por las asociaciones feministas. Sin embargo, la ley del divorcio, tanto en Cuba como en el resto de Latinoamérica, se erigió como un símbolo de la ruptura entre el modelo colonial y la nueva concepción liberal del Estado en la que la Iglesia perdía peso como instrumento para regular y categorizar las relaciones humanas. De esta forma, la Ley del Divorcio marcó un punto de inflexión en la redefinición de la ciudadanía de las mujeres en tanto que contribuyó a reconfigurar parte de las relaciones entre el Estado y la sociedad en el ámbito privado, confiriéndoles mayor entidad civil y libertad de actuación (MEDEROS, 1940; PRADO, 1999, p. 29-73; FRANCO; PRADO, 2009, p. 171-236).

Por otro lado, bien influidas por el mencionado concepto de la modernidad y el progreso que llegaba desde los EEUU, bien por el reciente pasado esclavista y la imperfecta integración de la población negra y mulata, las mujeres sufragistas perpetuaron las diferencias en función de la adscripción de los individuos a una determinada "raza" y de su clase mientras trataban de limar desigualdades políticas con los hombres. Así, según estas primeras asociaciones sufragistas, el voto habría de circunscribirse a las "mujeres alfabetas de buena conducta moral"; es decir, a las mujeres blancas, de clase media y que supieran leer y escribir, lo que dejaba fuera a la gran mayoría de mujeres (BARRITEAU, 1998, p. 197-202; PAGÉS, 2003, p. 51; ORTIZLOYOLA, 277, p. 5).

\section{GANPHLAC}

Revista Eletrônica da ANPHLAC, ISSN 1679-1061, №. 20, p. 141-172, Jan/Jun., 2016. 
El temor a la africanización de Cuba con la llegada de un volumen extraordinario de población esclava a lo largo del siglo XIX continuó vigente durante la República de Cuba (NARANJO OROVIO; PUIG-SAMPER, 1998, p. 11-21; HELG, 1996, p. 63-83; NARANJO OROVIO; GARCÍA GONZÁLEZ, 1996; NARANJO OROVIO, 2006). Contra la marginalización social de la población afrocubana, las mujeres negras y mestizas lanzaron algunas proclamas en publicaciones y partidos políticos poniendo de relevancia la represión social fundamentada en la raza. Algunas mujeres publicaron cartas en el periódico Previsión, vocero del Partido Independiente de Color (PIC), pero su participación fue mucho más asidua en Minerva, revista de la agrupación homónima integrada mayoritariamente por mujeres negras y mulatas (MONTEJO, 1998, p. 33-48). Entre 1910 y 1912, algunas de ellas se llegaron a implicar en los conflictos surgidos entre el PIC y el gobierno de José Miguel Gómez, tras lo cual miles de negros y mulatos fueron asesinados y se decretó la prohibición del PIC. Poco después, en un contexto hostil para la población afrodescendiente, la asociación Minerva terminó disolviéndose en 1914 (TORRES-ELERS, 2013, p. 121; MERIÑO FUENTES, 2006, p. 116). Si se analizan los volúmenes de Minerva y los artículos de Previsión, no se perciben cambios radicales a nivel discursivo en lo relativo a las mujeres afrocubanas ya que ni ellas ni sus compañeros cuestionaron el rol que desempeñaban dentro de sus círculos sociales. Podría decirse que lejos de reclamar medidas de carácter feminista en sus textos está mucho más presente la identidad racial que las reivindicaciones de género o las peticiones de reformas políticas concernientes a las mujeres. Por otra parte, si el movimiento sufragista en sus primeros momentos apenas integró a mujeres afrodescendientes, ellas no parecieron sentirse identificadas o atraídas por un movimiento de mujeres que quizás consideraban elitista y escasamente interesado en subvertir la pirámide social. Este mutuo desinterés permite afirmar que los prejuicios raciales quizás predominaban sobre la solidaridad de género.

La creación del mencionado Club Femenino en 1918 y la conformación de la Federación Nacional de Asociaciones Femeninas en 1921 coincidieron con el estallido de la Revolución de Octubre y la expansión del feminismo ruso por el mundo. El radicalismo de sus postulados en materia feminista frente al sufragismo norteamericano coincidió en Cuba con un movimiento regeneracionista que pretendía renovar tanto las instituciones, como las élites dirigentes. Sin embargo, lejos de provocar la unión de las clases marginadas, como reclamaban los comunistas, la radicalización social generó la fractura del movimiento femenino. En el I y el II Congreso

\section{GANPHLAC}

Revista Eletrônica da ANPHLAC, ISSN 1679-1061, №. 20, p. 141-172, Jan/Jun., 2016. 
Nacional, de 1923 y 1925, sufragistas y feministas protagonizaron algunos conflictos cuando algunas mujeres añadieron a las demandas estrictamente políticas, como el derecho al voto o la protección laboral, otras de carácter moral que cuestionaban la unidad familiar tradicional tales como el reconocimiento de los hijos ilegítimos o el aborto. Estos planteamientos, además, se vieron agravados por la promesa que Gerardo Machado hizo a las mujeres en 1925 de concederles el voto al tiempo que varios casos de malversación de fondos públicos salían a la luz (FEDERACIÓN NACIONAL DE ASOCIACIONES FEMENINAS, 1925). ${ }^{5}$

El año 1928 constituyó un punto bisagra en lo relativo a la historia del movimiento femenino en Cuba. La Habana acogió la creación de la Comisión Interamericana de Mujeres (CIM) bajo el auspicio de la Organización de Estados Americanos, aunque Cuba no fue miembro fundador. ${ }^{6}$ Aprobado el sufragio femenino en USA, Uruguay y Ecuador, abierto el debate sobre este mismo asunto en Cuba, Puerto Rico y Brasil, la creación de la CIM buscaba coordinar esfuerzos para que el sufragio femenino fuese aprobado en todos los países del continente, pero también como un canal de expresión para denunciar y paliar otro tipo de discriminaciones hacia las mujeres más allá del ámbito político. El mismo año se creó el Lyceum de La Habana por iniciativa de Renée Méndez Capote. Elena Mederos, una de sus fundadoras, actuó como eslabón el Lyceum y la CIM, labor en la que también destacarían Pilar Maza y María Luisa Guerrero (MEDEROS, 1952-53, p. 9-10; MEDEROS, 1981). ${ }^{7}$ Casi de forma simultánea nació la Alianza Nacional Feminista, que acentuó la secesión con los bloques más conservadores de las organizaciones femeninas. Sus estatutos seguían la línea oficial que marcó los dos primeros congresos, ampliando el abanico de demandas desde el sufragio femenino a otros marcos de actuación. Desde esta plataforma, Ofelia Rodríguez Acosta lideró la creación de la Unión Nacional Feminista, que luego se convertiría en la Unión Radical Feminista, una de las principales agrupaciones que se enfrentaron al régimen de Gerardo Machado en los años 30.

\footnotetext{
${ }^{5}$ La revista Social dio voz a muchas de las feministas y sufragistas de los años 20 y 30, ALONSO Nancy y YÁÑEZ, Mirta. Damas de social: intelectuales cubanas en la revista Social. La Habana: Ediciones Boloña, 2014, $333 \mathrm{p}$.

${ }^{6}$ La profesora Marysa Navarro desarrolla actualmente un proyecto en Harvard University para profundizar en el conocimiento de la agrupación a escala continental: NAVARRO-ARANGUREN, M. The Inter-American Commission of Women, the Pan American Union and Women's Suffrage in the Americas, 1928-1948. Visto en http://drclas.harvard.edu/people/marysa-navarro-aranguren.

${ }^{7}$ Más información en MEDEROS, Elena. In defense of Motherhood: Divorce Law in Cuba during the Early Republic. Disponibles en University of Miami, Cuban Heritage Collection, Fondo Elena Mederos, Caja 2.
}

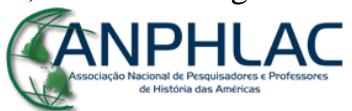

Revista Eletrônica da ANPHLAC, ISSN 1679-1061, №. 20, p. 141-172, Jan/Jun., 2016.

http://revista.anphlac.org.br 
Aunque durante el primer tercio del siglo XX las mujeres cubanas lograron motivar debates sobre el sufragio universal, apenas se prestó atención a los problemas particulares que afectaban a las mujeres negras y mulatas, que rara vez fueron invitadas o tuvieron la iniciativa de tomar parte en estos encuentros. La desarticulación social provocada tras la matanza de los miembros del PIC desmanteló las pocas agrupaciones donde las afrocubanas participaban, lo que probablemente dificultó su expansión hacia el espacio público y, por extensión, su interrelación con los movimientos feministas. Durante los años 1920-1930, mientras algunas élites intelectuales y académicas comenzaron a interesarse por la cultura afrocubana, los círculos políticos y científicos estrecharon lazos para concebir diferentes políticas de higienización social para ahuyentar el miedo a la africanización que provocaba la inmigración haitiana y jamaiquina, que por otro lado era mayoritariamente masculina (BRONFMAN, 2001, p. 23-33; NARANJO OROVIO; GARCÍA GONZÁLEZ, 1998, p. 437-449; GURIDY, 2003, p. 19-48). ${ }^{8}$ Junto a la persistencia de la marginalización de la población afrocubana las emergentes élites afrocubanas comenzaron a crear sus propias asociaciones de cultura y asistencialismo mutuo donde las mujeres participaron de las actividades literarias y culturales. Asociaciones como Club de Atenas, Atenas Occidental, Hijos de Maceo, Adelante: Asociación Pro-Cultura y Justicia o Antilla Sport Club contaron con un alto índice de participación femenina y en ocasiones crearon clubes de mujeres o damas dentro de sus estructuras. Si bien estas agrupaciones afrocubanas fomentaron su participación, lo cierto es que reprodujeron los estereotipos de género que pueden encontrarse en las familias blancas. Desde la revista Previsión del Partido Independiente de Color en 1912, hasta las actas de agrupaciones como el Frente Cívico Cubano contra la Discriminación en los años 50', se mantiene que las mujeres deben ser dueñas de su hogar, dedicarse a su cometido biológico de la reproducción, cuidar a sus hijos y recluirse en el espacio privado por su presunta incapacidad para enfrentarse con asuntos públicos (HIDALGO, 2012, p. 30-45; PIGNOT, 2010, p. 846-849; RAMÍREZ CHICHARRO, 2014, p. 812-818).

\footnotetext{
${ }^{8}$ Por otro lado, las estadísticas demuestran que la población afrocubana en general, y en especial las mujeres negras y mestizas, tenían bajos índices de criminalidad en el primer tercio del siglo XX, como afirma BRONFMAN, A. The allure of technology: photographs, statistics and the elusive female criminal in 1930s Cuba. Gender \& History, v. 19 , n. 1 , p. $60-77,2007$.
}

\section{CANPHLAC}

Revista Eletrônica da ANPHLAC, ISSN 1679-1061, №. 20, p. 141-172, Jan/Jun., 2016. 
La fraudulenta reelección de Machado para la presidencia coincidió con la crisis económica mundial de 1929 que convulsionó la economía cubana elevando los niveles de desempleo y las fricciones entre gobiernos, sindicatos y grupos de acción urbana (SOTO, 1977). En este clima de crisis política, económica y social, el movimiento femenino terminó dividiéndose en dos tendencias principales. Hasta 1930 ningún grupo feminista se había opuesto a la cuestión del voto para las mujeres. La lucha por el sufragio universal se había constituido como un elemento más de la llamada regeneración democrática iniciada a comienzo de los años 20', pero las continuas demandas lo habían terminado convirtiendo en un motivo de especulación política. Las tímidas concesiones que Gerardo Machado hizo a las feministas y sus incumplidas promesas tambalearon el clima de opinión dentro del movimiento feminista. Algunas mujeres interpretaron la petición del voto femenino como un gesto de condescendencia con un sistema corrupto, mientras otras desarrollaron intensas campañas de concienciación y solicitud del voto entre 1932 y 1934. En la lucha por el sufragismo, las mujeres contaron no solo con el beneplácito, sino con el activismo de muchos parlamentarios que se unieron a sus reivindicaciones (ALIANZA NACIONAL FEMINISTA, 1948, p. 16-20; RODRÍGUEZ VILLAMIL; SAPRIZA, 1984; STONNER, 2003, p. 151-177).

Cuando la situación política se agravó, entre 1931 y 1933, Gerardo Machado comprendió que las mujeres más radicales se habían constituido en un nuevo frente de oposición política no tanto por sus reivindicaciones feministas como por la oposición a su gobierno. Se ordenó reforzar los cuerpos policiales con la creación de las llamadas porras femeninas, escuadrones de mujeres instruidas para el combate y ordenó reprimir a las mujeres que incitasen a la insurrección. De hecho, mientras en el cortejo funerario del estudiante Trejo, convertido en mártir de la oposición política, los soldados no reprimieron a las mujeres que encabezaban la marcha, en los meses sucesivos las integrantes de la Unión Radical de Mujeres y la Alianza Nacional Feminista fueron especialmente perseguidas. El 8 de marzo de 1931 varias mujeres fueron detenidas por aprovechar la celebración del Día del a Mujer para criticar al régimen de Machado. Las trabajadoras del Centro Obrero, coordinadas con la CNOC y la Federación Obrera, fueron desalojadas por la policía cuando Panchita Batet comenzó a criticar al presidente. Por su parte, Libertad Briones fue detenida cuando comenzó a hablar de Clara Zetkin, la líder marxista y feminista alemana, en el Sindicato de Torcedores de Santiago de Cuba. Este mismo sindicato en La Habana dio primeramente su apoyo a la celebración del

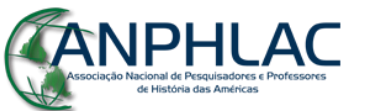

Revista Eletrônica da ANPHLAC, ISSN 1679-1061, №. 20, p. 141-172, Jan/Jun., 2016.

http://revista.anphlac.org.br 
homenaje a Trejo que pretendían organizar mujeres como Ofelia Rodríguez Acosta, Loló de la Torriente, Teresa Casuso u Ofelia Domínguez, presidenta de la Alianza Nacional Feminista. Sin embargo, presiones gubernamentales impidieron que las mujeres pudieran finalmente celebrar el acto (PAGÉS, 1991, p. 10; PAGÉS, 2000, p. 125; TORRIENTE BRAU, 2001, p. 100-104; STONNER, 2003, p. 168).

Objeto de represalias fueron mujeres como Toro Abril a quien le fracturaron tres costillas en las movilizaciones organizadas por la Escuela Normal de Santiago de Cuba, o María Josefa Vidaurreta, compañera del periodista Juan Marinello, quien fue hecha presa por su militancia comunista (IRIS DAVILA, 1976, p. 10-12; TORRIENTE BRAU, 2001, p. 108). La presencia de mujeres activistas comunistas en la revolución de 1933 puede rastrearse también en la constitución del soviet de Mabay, donde junto a varios hombres tomaron la iniciativa de expropiar y declarar nulas todas las deudas (ECHEVERRÍA, 1977, p. 16-17; GONZÁLEZ CABRERA, 1983, p. 15-17). Decenas de mujeres fueron encarceladas como opositoras al régimen de Machado. Rosa Pastora Leclerc Zoila Mulet, Neneína Castro o Calixta Guiteras, que trabajó junto a su hermano, el revolucionario Antonio Guiteras, pasaron por la cárcel de Isla de Pinos durante aquellos años (CASADO FERNÁNDEZ, 2012, p. 195-205). ${ }^{9}$ Otras mujeres activistas fueron asesinadas, como America Labadi, integrante de la Liga Comunista de Jóvenes Cubanos, que fue detenida en la redada policial del 1 de agosto de 1933, diez días antes de que Machado abandonase el poder (ECHEVERRÍA, 1977, p. 16-17). Ante el creciente control policial, Ofelia Rodríguez y Candita Gómez, nieta del general Máximo Gómez, encabezó una marcha de mujeres del Directorio Revolucionario y de la Escuela Normal hasta el cuartel militar de Columbia para pedir al General Castillo que las protegiese de los ataques policiales, pero el ejército eludió inmiscuirse en asuntos políticos (TORRIENTE BRAU, 2001, p. 113-115).

La mayoría de las mujeres que participaron en este movimiento insurreccional continuó en el activismo social y político durante los años cuarenta. Rosa Pastora, por ejemplo, creó la Asociación del Auxilio al Niño del Pueblo Español para los exiliados de la Guerra Civil y llegaría a ser vicepresidenta del Partido Ortodoxo, junto a Eduardo Chibás. Por su parte, Calixta Guiteras trabajó primero junto a su hermano, el revolucionario Antonio Guiteras, y luego se

\footnotetext{
${ }^{9}$ Dos testimonios de mujeres en las cárceles se encuentran en RODRÍGUEZ ACOSTA, O. De seis a seis. La vida en las prisiones cubanas. México D. F.: s.e., 1937 y GONZÁLEZ, E. Estampas de la cárcel. La Habana: S.f.
}

\section{GANPHLAC}

Revista Eletrônica da ANPHLAC, ISSN 1679-1061, №. 20, p. 141-172, Jan/Jun., 2016. 
presentó por el Partido Ortodoxo como aspirante al Senado por La Habana junto a Fidel Castro en las elecciones de 1950 (ANÓNIMO, 1949; NARANJO OROVIO, 1988, p. 89-94).

Tras el derrocamiento de Machado, Ramón Grau de San Martín aprobó por decreto el sufragio femenino en enero de 1934. Cuba se convirtió en el quinto país latinoamericano en conceder el voto a las mujeres, tras Uruguay, Puerto Rico, Ecuador y Brasil. Este cambio de paradigma constituyó un punto de inflexión tanto para los partidos políticos como para el movimiento feminista. Por un lado, los partidos políticos crearon secciones femeninas dentro de sus estructuras con el fin de capitalizar por medio de la militancia y el adoctrinamiento al nuevo electorado que se incorporaba al sistema político. Agrupaciones como el Club de Mujeres Auténticas, Acción de Mujeres Auténticas, Unión de Mujeres Asociadas o Unión de Mujeres Socialistas Democráticas implicaron a un amplio número de mujeres en campañas electorales, manifestaciones públicas, tratados internacionales y debates políticos en la prensa y en la radio (UNIÓN DE MUJERES ASOCIADAS, 1949). ${ }^{10}$ Por su parte, las feministas pasaron a integrar progresivamente las estructuras del poder político como el senado y el parlamento, lo que les permitió elevar propuestas de reforma a las instituciones. Ahora bien, la presencia de las mujeres en el Parlamento jamás superó el 15\% del total de representantes y las medidas que propusieron o bien no fueron atendidas, o bien no iban encaminadas a mejorar específicamente la situación de las mujeres (RIERA, 1953; RIERA, 1955; COFFIGNY, 2008, p. 185-197).

\section{Más allá del sufragismo: la proyección pública de las mujeres bajo el régimen constitucional 1940-1952}

El III Congreso Nacional de Mujeres, de 1939, fue organizado por docenas de asociaciones femeninas bajo el eslogan "Por la mujer, por el niño, por la paz, por el progreso en Cuba". Estos cuatro puntos delimitarían, en síntesis, las discusiones de las mujeres participantes en la posterior asamblea constituyente, pero también los campos de actuación de las asociaciones femeninas tras la aprobación de la Constitución de 1940. El nuevo marco

\footnotetext{
${ }^{10}$ Algunos ejemplos son ARCHIVO NACIONAL DE CUBA. Registro de Asociaciones. Legajo 348, Expediente 10337, Club de mujeres Auténticas, p. 1-10, ARCHIVO NACIONAL DE CUBA. Registro de Asociaciones. Legajo 215, Expediente 5233, Unión femenina del Partido Demócrata, ARCHIVO NACIONAL DE CUBA. Registro de Asociaciones. Legajo 256, Expediente 6971, Unión de Mujeres Socialistas Democráticas.
}

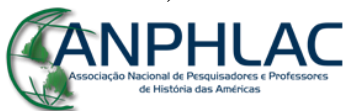

Revista Eletrônica da ANPHLAC, ISSN 1679-1061, №. 20, p. 141-172, Jan/Jun., 2016. 
legislativo redefinía cuestiones relativas a la familia y la igualdad en el ámbito laboral y prohibía todo tipo de discriminación por cuestión de género, raza, clase o religión. Sin embargo, a pesar de la que la nueva Carta Magna fue aprobada, durante su primer año en vigor apenas se desarrollaron 18 de las 287 leyes complementarias que se requería para poner en funcionamiento el nuevo marco constitucional. El Tribunal de Garantías Constitucionales y Sociales proyectado en 1940 no funcionó hasta 1949 por lo que el sistema judicial con el Tribunal Supremo al frente, se regía por la jurisprudencia establecida a partir de la Constitución de 1935. Además, el nuevo Código Civil de 1950 contradecía en algunos puntos a la Constitución de 1940, tales como en la patria potestad compartida, el derecho de las mujeres a iniciar su propio negocio o el libre ejercicio del voto sin permiso del marido. Es decir, aunque el marco legislativo que establecía la Constitución de 1940 resultaba potencialmente muy innovador para favorecer la igualdad de hombres y mujeres, los mecanismos para ponerlo en marcha se dilataron en el tiempo sin llegar a funcionar antes del golpe de Estado de Fulgencio Batista en1952 (CRUZ-TAURA, 1994, p. 133-136; GARCÍA BELAUNDE, 2004, p. 283-312).

A nivel legislativo, las mujeres afrocubanas consiguieron que el III Congreso Nacional de Mujeres y la asamblea constituyente discutiesen y aprobasen medidas contra la discriminación por raza y género. Sin embargo, durante los años cuarenta las mujeres negras y mulatas siguieron reclamando igualdad, representatividad, derechos y medidas contra la segregación. El sentido igualitario del progreso defendido por las asociaciones y partidos comunistas acercó a cada vez un mayor número de mujeres a la Unión Revolucionaria Comunista, el Partido Socialista Popular y a la Federación Democrática de Mujeres Cubanas (KEOSHA, 2011, p. 254-303). Durante este periodo, estas agrupaciones pidieron al gobierno que afrontase el problema de la prostitución y tomase medidas en lo relativo a los hijos ilegítimos, que mayoritariamente afectaba a las mujeres afrodescendientes. Sin embargo, a pesar de la campaña antidiscriminatoria que las activistas afrocubanas llevaron a cabo en esta época, todavía puede constatarse en la prensa que las mujeres negras y mestizas eran perseguidas y encarceladas por supuestas prácticas de brujería (GONZÁLEZ, 1950, p. 83-93). Por otro lado, el auge de una nueva burguesía negra y mestiza en La Habana y Pinar del Río, así como en Santiago, elevó a algunas de estas mujeres a un estatus privilegiado y excepcional que no se correspondía con la situación que padecía la mayoría de estas mujeres (PIGNOT, 2010, p. 837-862).

\section{GANPHLAC}

Revista Eletrônica da ANPHLAC, ISSN 1679-1061, №. 20, p. 141-172, Jan/Jun., 2016. 
A nivel general, durante la República, las mujeres cubanas redujeron sus niveles de analfabetismo y un número cada vez mayor comenzaba a matricularse en la universidad. Sin embargo, puede apreciarse cómo el alfabetismo era mayor entre las mujeres blancas que entre las mujeres negras, lo que permite constatar cómo las diferencias raciales persistían incluso en el censo de 1943, el último que recogió específicamente datos sobre la población blanca, mestiza y mulata. También se aprecia cómo las mujeres cubanas elegían su formación profesional respondiendo a los estereotipos de género del periodo de entreguerras. Las familias cubanas defendían que las mujeres debían cuidar y educar a su descendencia, lo que trasladado al campo de universitario las obligaba a inclinarse por carreras como la enfermería, las ciencias humanas y el magisterio (REPÚBLICA DE CUBA, 1908, 1921, 1931, 1945, 1953; LAMAR, 1923).

En el terreno laboral, las mujeres no solo aumentaron su presencia en términos absolutos durante toda la República, sino que comenzaron a ser contratadas en un más amplio abanico de trabajos. Sin embargo, se aprecia un progresivo blanqueamiento de del mercado laboral. Las mujeres afrocubanas, lejos integrarse en nuevas áreas, comenzaron a perder presencia en puestos que tradicionalmente habían desempeñado, como el servicio doméstico o la costura, en favor de mujeres blancas mejor cualificadas, una situación que las empujaba a desempeñar la prostitución u otros oficios no registrados en el censo (SOUSA; SANTOS, 2007, p. 55-56 y 94100; RAMÍREZ CHICHARRO, 2015, p. 800-812). Solo el 13\% de las mujeres cubanas tenía empleo remunerado, lo que representaba apenas un $10 \%$ del mercado laboral cubano a la altura de 1954 (IBARRA, 1995, p. 162). Esta presencia sirvió para que las mujeres llegasen a crear sus propios sindicatos en los ocupaciones donde eran mayoría, como las despalilladoras o torcedoras. No obstante, también se incorporaron a los grandes sindicatos nacionales. Según la Confederación Internacional de Sindicatos Libres, a la altura de 1956 el principal sindicato cubano de trabajadores, la CTC, contaba entre su membresía con el mismo porcentaje de mujeres que sus homólogos alemán y belga y muy cerca de los daneses y noruegos. ${ }^{11}$

\footnotetext{
${ }^{11}$ La INTERNATIONAL CONFEDERATION OF FREE TRADE UNIONS. Preparatory committee on questions dealing with women workers. Bruselas, 14 Febrero 1956, anexo 1. Señala que la proporción de mujeres en los sindicatos de diferentes países era Tailandia un 57\%, Israel 42\%, Suecia 37\%, Austria, 25\%, Australia 22\%, Dinamarca 18\%, Noruega 17\%, Cuba 16,7\%, Bélgica 15,7\%, Alemania 13,9\%, Colombia, 12,1\%, Túnez 5,66\%, España 3,26\%, Madagascar 2,6\%, Camerún 0,19\%. Disponible en http://wasi.alexanderstreet.com.ezpprod1.hul.harvard.edu/view/1688626 (20 noviembre 2015).
} 
El contexto nacional e internacional favoreció que las mujeres se inclinasen por labores sociales y asistenciales alejadas de las reivindicaciones feministas que se habían llevado a cabo durante el primer tercio del siglo XX. Los diferentes conflictos bélicos, como la Guerra Civil Española o la Guerra de Corea, llevaron a dejar de lado las demandas feministas y a desarrollar una nuevo activismo de carácter humanitario. Las mujeres cubanas concentraron sus esfuerzos en enviar suministros alimenticios a las áreas afectadas por las contiendas y a acoger refugiados políticos. ${ }^{12}$ De igual forma, la II Guerra Mundial tuvo repercusiones en el activismo sociopolítico de las mujeres cubanas. Entre 1941 y 1942, Fulgencio Batista publicó una serie de medidas para movilizar a las mujeres cubanas en la defensa de la isla. Aunque Cuba no fue atacada por las potencias del Eje, María Gómez Carbonell, ministra sin cartera entre 1940 y 1944, sugirió que las mujeres desempeñasen un papel activo en la retaguardia, organizando a los niños, asegurando el suministro de víveres para la población y asistiendo tanto a los cuerpos militares como a los refugiados que llegasen a los puertos. ${ }^{13}$ En este contexto, los medios de comunicación llevaron a cabo una campaña mediática que puso en valor el la predisposición de las mujeres en general, y el trabajo de las enfermeras en particular. De esta forma se consolidó la imagen de las funcionarias sanitarias como cuidadoras del "hogar nacional" y protectoras de los hijos de la patria. En paralelo, el Lyceum de La Habana, con Elena Mederos al frente, tomó la iniciativa de crear una escuela de servicio social para ofrecer a algunas mujeres una formación regulada y una cobertura legal en tareas que ya venían desempeñando en casas de beneficencia y organizaciones asistenciales (DEL PORTAL, 1950, p. 58-60 y 112).

Hacia el final de la II Guerra Mundial y el comienzo de la Guerra Fría, las mujeres comunistas comenzaron a cobrar mayor relevancia en Cuba. El imaginario de feministas rusas como Clara Zetkin y Alexandra Kollontai influyó en líderes cubanas como Elena Gil, Nila Ortega y Edith García Buchaca, quienes movidas por la ideología y el imaginario soviético trabajaron en asociaciones culturales y educativas desde final de los años 30'. En 1946, bajo el auspicio de la Federación Internacional Democrática de Mujeres, fundaron la Federación

\footnotetext{
${ }^{12}$ Como se recoge en varios artículos de prensa: S.A. American women's unit in Cuba reports arrival of all goods sent to Britain. The Christian Science Monitor, 4 Octubre 1941, p. 3, S.A. Cuban aid to the Allies. The Times, 11 January 1944, p. 5. Rosa Pastora llegaría a convertirse en vicepresidenta de Eduardo Chibás en el Partido Ortodoxo como indica NARANJO OROVIO, C. Cuba, otro escenario de lucha: la guerra civil y el exilio republicano español. Madrid: CSIC, 1988, p. 89-94.

${ }^{13}$ Como se observa en GÓMEZ CARBONELL, María. La mujer cubana y la guerra. Vanidades, v. 9. n. 17, 1 septiembre 1942, p. 14.
}

\section{GANPHLAC}

Revista Eletrônica da ANPHLAC, ISSN 1679-1061, №. 20, p. 141-172, Jan/Jun., 2016. 
Democrática de Mujeres Cubanas. Si por un lado sus integrantes se volcaron en promocionar la paz en el mundo, los derechos de las mujeres y la protección de los menores, por otro se mostraron muy críticas con el gangsterismo, la corrupción y la malversación de fondos de los gobiernos auténticos de Ramón Grau de San Martín y de Prío Socarrás (PIEPER MOONEY, 2013). ${ }^{14}$

Las reformas políticas implementadas y la expansión de las mujeres hacia el espacio público fueron interpretadas como medidas que terminarían desestabilizando la unidad familiar de carácter patriarcal. Este cambio de paradigma fue difundido por la prensa, que alertaba sobre el peligro de que las mujeres más activas en el espacio público pudieran alejarse de su cometido natural: la procreación y el cuidado de los hijos (REYNOLS 1943; CHEASLEY, 1945; MARTÍNEZ SIERRA, 1945; GARCÍA TUDURÍ GOYA, 1948; FINKELMAN, 1949). En respuesta, algunas mujeres universitarias y empleadas en sectores privados se pusieron a la vanguardia reclamando su capacidad para compatibilizar las esferas políticas, profesional y familiar, pero sin cuestionar, por otra parte, su papel subordinado respecto a los hombres como cabezas de la unidad familiar (ANDERSON, 1944; SORAVILLA, 1941).

\section{La dictadura de Batista: oposición política, mecenazgo y asistencialismo (1952-1959)}

El relevo generacional es un factor a tener presente en lo relativo al papel desempeñado por las mujeres en la oposición contra Batista. Las mujeres actuaron junto a los hombres desde distintos frentes y con diferentes experiencias políticas (KLOUZAL, 2008; CHASE, 2010; CHASE, 2015). Algunas habían sido agentes activos en el derrocamiento de Gerardo Machado veinte años atrás, como Carmen Castro, otras apenas habían alcanzado la mayoría de edad cuando se produjo el alzamiento de Batista, como Gladys García o Josefina Rodríguez. A pesar de que pueden rastrearse algunas agrupaciones feministas como la Avanzada Popular Femenina

\footnotetext{
${ }^{14}$ Mujeres Cubanas fue su principal publicación. Puede ser encontrada de forma fragmentada en Women's Movement in Cuba, 1898-1958: The Stoner Collection on Cuban Feminism y la Biblioteca Nacional José Martí de Cuba. Noticias referentes a su actuación también aparecen frecuentemente en el periódico del Partido Socialista Popular, Noticias de Hoy. Más información sobre sus actividades y su ideología en SUÁREZ, G. El lugar del pensamiento marxista en el contexto nacional de los años 40 y 50. Revista Cubana de Filosofía. Edición Digital. Disponible en http://revista.filosofia.cu/debate.php?id=657, 1 septiembre 2014.
}

\section{GANPHLAC}

Revista Eletrônica da ANPHLAC, ISSN 1679-1061, N. 20, p. 141-172, Jan/Jun., 2016. 
Nacional, presidida por Josefa Leyett, la mayoría de las organizaciones mencionadas quedaron sin efecto o redujeron su actividad, a excepción del Lyceum y Lawn Tennis Club. ${ }^{15}$ Dentro de la oposición, tanto la ideología, como los procesos de concienciación que movilizaron a las mujeres fueron muy diversos, así como sus estrategias de actuación. Si el sufragismo marcó las actividades públicas de las mujeres hasta 1934 y la solidaridad y la filantropía hasta 1952, desde ese momento en adelante las agrupaciones de mujeres dejarían a un lado las reivindicaciones feministas para decantarse por una vertiente nacionalista y revolucionaria de la justicia social y la legalidad constitucional que concentraba sus esfuerzos en derrocar la dictadura y reimplantar el sistema democrático depuesto (IBARRA, 1995, p. 174-180; GARCÍA-PÉREZ, 1999, p. 114).

El alzamiento militar liderado por Fulgencio Batista en marzo de 1952 constituyó la respuesta por parte del ejército a la incapacidad de gestionar los problemas nacionales, como el gangsterismo y la corrupción política, que parecía mostrar el gobierno de Carlos Prío Socarrás. Batista publicó unos Estatutos constitucionales que sustituirían a la Constitución y prometió la convocatoria de elecciones generales. El golpe de Estado dejó sin respuesta a la ciudadanía, que apenas ofreció resistencia en los primeros meses, y desarticuló a una oposición política que no supo establecer un frente común de actuación. Tanto el Partido Auténtico como el Partido Ortodoxo se dividieron en facciones internas que discutían si presentarse o abstenerse en unas elecciones convocadas por un líder militar que había desmantelado el pacto constitucional. En un primer momento, solo las facciones más radicales dentro de estas formaciones se decantaron por la acción armada, mientras el PSP se mostró más beligerante en el terreno mediático y en la organización de algunas huelgas azucareras e industriales, al menos hasta 1958.

El golpe de Estado de Batista, pero sobre todo la ascendente violencia política, reactivó a la oposición antimachadista que incorporó a una nueva generación de mujeres plagada de ideales. En aquellos años, la lucha por ampliar los derechos de la mujer pasó a un segundo plano, constituyendo apenas el epílogo de un programa político más ambicioso. Las mujeres empezaron a pensar que modificar la legislación que sustentaba las relaciones de género no mejoraría su posición dentro del sistema, sino que había que cambiar de raíz el sistema político para crear un nuevo tipo de vínculos sociales. Sin embargo, ni en las organizaciones

${ }^{15}$ ARCHIVO NACIONAL DE CUBA, Fondo de Asociaciones, Legajo 178, Expediente 3643, p. 5.

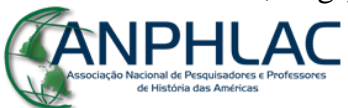

Revista Eletrônica da ANPHLAC, ISSN 1679-1061, No. 20, p. 141-172, Jan/Jun., 2016. http://revista.anphlac.org.br 
clandestinas de la oposición, ni en los focos guerrilleros de las montañas, donde se clamaba por la igualdad y la justicia política, se aprecia un nuevo equilibrio de poderes y reparto de roles entre hombres y mujeres (RAMÍREZ CHICHARRO, 2016).

Los frentes desde los que actuaron las mujeres fueron numerosos y en ocasiones estuvieron intensamente conectados. La salida negociada del conflicto estuvo encabezada por la Sociedad de Amigos de la República (SAR), una agrupación de asociaciones cívicas coordinadas por Cosme de la Torriente, Jorge Mañach y José Miró Cardona. Dos mujeres de larga trayectoria política en Cuba tuvieron gran presencia como intermediarias en estos conflictos: Pilar Maza y Elena Mederos, quien como se ha mencionado era una de las dirigentes del Lyceum y representante de Cuba en la Comisión Interamericana de Mujeres.

En las ciudades hubo divergencias a la hora de elegir la mejor estrategia para vencer a la dictadura, más aún conforme el régimen cerró el cerco a la oposición. La indecisión y falta de iniciativa de las principales formaciones políticas motivaron la actuación de nuevos agentes políticos. En un primer momento, se organizaron campañas de propaganda y pequeños disturbios urbanos para crear un clima de opinión favorable a los revolucionarios. En esta labor destacaron las mujeres comunistas, ortodoxas y el alumnado universitario. La Federación Democrática de Mujeres Cubanas, si bien ya había hecho patente su vertiente comunista desde los años 40, en los años 50' se radicalizó para enfrentar a la dictadura de Batista y promovió campañas de concienciación para criticar al nuevo régimen. En un contexto marcado por la Guerra Fría entre bloques y el final de las relaciones diplomáticas entre Batista y la URSS inclinaron al gobierno cubano hacia la esfera estadounidense y por tanto contra todo elemento comunista. En paralelo, se asaltaron las casas editoriales de periódicos como La calle y Noticias de Hoy, del Partido Comunista, o revistas como Mujeres de la Federación Democrática de Mujeres Cubanas. ${ }^{16}$ Por su parte, las mujeres ortodoxas se aglutinaron en el Frente Cívico de Mujeres Martianas, que quizás fue la organización femenina más activa de entre las citadas. Fundado por Aida Pelayo y Carmen Castro, aglutinó en sus filas a mujeres blancas procedentes

\footnotetext{
${ }^{16}$ En la prensa aparecieron varias fotografías sobre las actuaciones del SIM contra la FDMC: Destroza el S.I.M. las propiedades de la FDMC. Noticias de Hoy. La Habana, 12 de febrero de 1953, p. 1. La maestra, Clementina Serra, la despalillador, Julia León, y la militante de la sección femenina del Partido Ortodoxo, Doctora María Esther Villoch, denunciaron en la prensa las agresiones de las que fueron objeto por la policía: Protesta ante el Ministro de Gobernación la Federación Democrática de Mujeres. Noticias de Hoy. La Habana, 15 de febrero de 1953 , p. 1 y 8.
}

\section{CANPHLAC}

Revista Eletrônica da ANPHLAC, ISSN 1679-1061, №. 20, p. 141-172, Jan/Jun., 2016. 
de la clase media urbana. Su estructura se extendía a nivel nacional, aunque los núcleos fuertes se encontraban en La Habana y Santiago de Cuba. Divididas en diferentes secciones, destacaron por su papel en la propaganda panfletaria y la acción directa (CASTRO PORTA, 2004). Las divergencias dentro de la organización sobre la inclusión o no de las mujeres comunistas en sus filas, dieron pie a que una facción de sus integrantes fundase Mujeres Oposicionistas Unidas en 1956, donde tuvieron cabida mujeres de diferentes ideologías políticas, pero cuyo único objetivo era derrocar la dictadura de Batista (MUJERES OPOSICIONISTAS UNIDAS, 1958).

Más que los mártires de la historia cubana como Martí, Mella, Trejo o el propio Chibás, el verdadero catalizaron de la acción política contra Batista fue el asesinato de los primeros opositores. Una parte de las estudiantes procedente de las facultades de humanidades, pedagogía y enfermería de la Universidad de La Habana, e integradas en la Federación Estudiantil Universitaria, lideraron varias manifestaciones desde la Universidad hacia los principales puntos neurálgicos de la ciudad. Dos de las más multitudinarias fueron la marcha en el aniversario de la muerte de Eduardo Chibás, líder del Partido Ortodoxo, en agosto de 1952, así como las movilizaciones para denunciar el asesinato de Rubén Batista, estudiante universitario, en febrero de 1953 (GARCÍA OLIVEIRA, 2006; SOLAR CABRALES, 2013, p. 129-139).

Tras estos acontecimientos, una facción del estudiantado en Cuba se inclinó progresivamente por la acción armada, sobre todo tras la sensación de que la vía negociada que proponía la SAR se había estancado. En abril de 1953, Rafael García Bárcena, profesor de filosofía en la Universidad de La Habana y dirigente del grupo opositor llamado Movimiento Nacional Revolucionario, aglutinó a decenas de estudiantes en la preparación de un complot contra el Campamento militar de Columbia. Sin embargo, la policía desmanteló la conspiración en la que estaban participando varias mujeres, como Marta Fray de Barraqué, Delia López Puncet, Herminia Delfín Charles, Ana Luisa Capote y Eva Jiménez, quien fue enviada al reclusorio de mujeres de Guanajay (GARCÍA PÉREZ, 2009, p. 63-66). Por su parte, Haydée de Santamaría y Melba Hernández participaron en el intento de tomar los cuarteles de Moncada y Bayamo por parte de la juventud ortodoxa más radical liderada por Fidel Castro.

Tras la liberación de los asaltantes a los cuarteles de Moncada y Bayamo, una facción del Partido Ortodoxo fundó el Movimiento Revolucionario 26 de Julio (MR26J). Esta organización de carácter nacional pretendía constituirse en el principal grupo de cívico y militar

\section{GANPHLAC}

Revista Eletrônica da ANPHLAC, ISSN 1679-1061, №. 20, p. 141-172, Jan/Jun., 2016.

http://revista.anphlac.org.br 
de oposición a Batista, tanto en el interior de la isla como en el exilio (ACCIÓN CÍVICA CIUDADANA, 1957; SECCIÓN FEMENINA DE ACCIÓN CÍVICA CUBANA). ${ }^{17}$ Parte del estudiantado, junto a simpatizantes del Partido Auténtico, entre los que había un amplio número de mujeres, crearon el Directorio Revolucionario (DR) con el apoyo financiero de Carlos Prío Socarrás desde el exilio de Miami. Dejando a un lado las manifestaciones, sus integrantes fueron entrenados en el manejo de armas y bombas sin metralla y practicaron el terrorismo urbano con atentados personales a cuerpos policiales. El MR26J y el DR pactaron, en agosto de 1956, derrocar a la dictadura de Batista por la vía armada. Sin embargo, ambos grupos divergían en las vías para conseguirlo. Mientras el MR26J quería crear un estado de concienciación mediante el llamado foquismo, el Directorio quería atacar directamente a la cúpula. Mujeres como Mary Pumpido o Natalia Bolívar participaron de los preparativos, la financiación y la búsqueda de apoyos políticos para emprender el fracasado asalto al Palacio Presidencial del 13 de marzo, si bien solo Natalia integró la vanguardia del ataque. Por su parte, el MR26J, autofinanciado por la ciudadanía simpatizante, la contribución de sus miembros y el apoyo de sus secciones en el extranjero, puso en funcionamiento grupos de instrucción, propaganda y sabotaje. Las mujeres, bien mediante sus hermanos y maridos, bien a través de sus vecinos o por iniciativa propia, fueron integrándose en sus filas, pero nunca existió una sección femenina en ninguna de las dos organizaciones. Mujeres como Celia Sánchez, Vilma Espín, María Ruiz Bravo, Doyla Noa o Asela de los Santos, ocultaron combatientes, importaron armas, imprimieron periódicos en la clandestinidad y trasladaron a los compañeros que querían alzarse para combatir en la Sierra. Sin embargo, aunque en septiembre de 1958 Fidel Castro creó en el I Frente de combate el "Pelotón Mariana Grajales", solo una decena de mujeres conformó sus filas. Liderado por Isabel Rielo y Teté Puebla, actualmente la única Coronel del Ejército Cubano, protagonizaron batallas como Cerro Pelado (septiembre de 1958) y Güiros (noviembre de 1958) (WATERS, 2003). En el resto de frentes guerrilleros que enfrentaron la dictadura, también hay presencia de mujeres, pero más frecuentemente en tareas de carácter civil que en acciones militares (MARTIN, 1976; DE LOS SANTOS; ESPÍN; ÁLVAREZ MOLA, 2011; RAMÍREZ CHICHARRO, 2016).

\footnotetext{
${ }^{17}$ Como se aprecia en: Para rendir tributo ninguna voz es débil. Batalla, Miami, 4 de agosto 1957. Haydée de Santamaría y Dysis Guira fueron dos de las activistas del MR26J y del DR más activas en el extranjero.
}

\section{BANPHLAC}

Revista Eletrônica da ANPHLAC, ISSN 1679-1061, №. 20, p. 141-172, Jan/Jun., 2016. 
Mientras las mujeres desafectas al régimen de Batista pasaron a integrar las filas de la oposición, otras veían en Martha Fernández Miranda de Batista, la esposa del dictador, el modelo de mujer acomodada que se comprometía con los problemas de la nación (MARQUINA, 1952, p. 64-66; ANÓNIMO, 1953, p. 81). La Asociación de Confraternidad Femenina Progresista establecía en sus estatutos que trabajaría por el progreso de las mujeres para hacer "de cada madre una Mariana Grajales heroica [...] una Martha Fdez de Batista, una Emelina Jiménez del Pozo", uniendo en un solo haz las mujeres que lucharon por la independencia y aquellas que preservaban "la paz, la cultura, el orden y el bienestar". ${ }^{18} \mathrm{Al}$ contrario que en otros periodos, durante la dictadura de Batista es posible apreciar una mayor interrelación e incluso injerencia gubernamental en las asociaciones feministas. Leonor Crespo Giró, secretaria en la Avanzada Popular Femenina, trabajaba en el mismo puesto dentro de la Liga Nacional Femenina Electoralista, que se formó en julio de 1956 para apoyar al partido de Batista ante las elecciones generales que se celebrarían en $1958 .{ }^{19}$ Zoila Leiseca presidió la comisión de "Problemas de la mujer" dentro del Ateneo de la mujer, que funcionó entre 1955 y 1960, mismas fechas en las que sería elegida como candidata al congreso por Ciego de Ávila o Camagüey dentro del Partido Acción Progresista de Batista (HERRERA VALDÉS; COFFIGNY, 2001-2002). Evangelina de la Llera, presidenta del Directorio Nacional Femenino del Partido Unión Radical de Fulgencio Batista, dirigió asimismo la Acción Nacional de Mujeres Batistianas desde 1955 y llegó a ser ministra sin cartera durante el segundo gobierno de Batista. ${ }^{20}$

El activismo asistencial y benéfico de las mujeres en Cuba, si bien estuvo presente a lo largo de todo el siglo, en los años cincuenta incrementó su visibilidad debido al mecenazgo ejercido por Martha Fernández de Batista. Las Ligas Antituberculosa, contra la Ceguera y Contra el Cáncer estuvieron especialmente activas en la recaudación de fondos a través de campañas y colectas con los que financiar el tratamiento médico a aquellas familias que no podían afrontar los gastos. En estrecha colaboración, el asociacionismo católico, por su parte, desde valores como la filantropía, el humanitarismo y la caridad, acaparó la atención de un gran

\footnotetext{
${ }^{18}$ ARCHIVO NACIONAL DE CUBA, Fondo de Asociaciones, legajo 193, expediente 4259.

${ }^{19}$ ARCHIVO NACIONAL DE CUBA, Fondo de Asociaciones, legajo 158, expediente 2805, p. 6-11

${ }^{20}$ ARCHIVO NACIONAL DE CUBA, Fondo de Asociaciones, legajo 157, expediente 3187 y legajo 178, expediente 3610 .
}

\section{CANPHLAC}

Revista Eletrônica da ANPHLAC, ISSN 1679-1061, №. 20, p. 141-172, Jan/Jun., 2016. 
número de mujeres que vieron en sus actividades una forma de poner en práctica sus creencias religiosas. En esta época, el asociacionismo católico se dividía, a grandes rasgos, en institucional y estudiantil. Entre las primeras, las Damas Católicas colaboraron en numerosas ocasiones con las mencionadas ligas financiando y procurando asistencia a los sectores más desfavorecidos de la sociedad, mientras las segundas solían ocuparse de tareas como el reparto de juguetes, ropa o comida entre los mismos grupos. Las mujeres también actuaron en el seno de la iglesia católica como una agente para promover ciertos valores cívicos entre la ciudadanía. Por ejemplo, aquellas que integraron la Liga de la Decencia denunciaron el alcoholismo y exigieron ciertas normas de "moralidad" en el cine. ${ }^{21}$

\section{Conclusión}

La acción cívica y política de las mujeres cubanas durante la República puede interpretarse como la reacción de un sector de población frente a un sistema que no les reconocía como ciudadanas con plenos derechos, ni participar en las estructuras del poder. Durante el primer tercio del siglo XX, las reivindicaciones sufragistas en América y Europa coincidieron en Cuba con un proceso de construcción nacional marcado por movimientos de regeneración política que buscaban hacer de las instituciones estatales instrumentos más efectivos y representativos. En este contexto, las mujeres cubanas se agruparon en diferentes asociaciones que luego se unieron en frentes de acción común para solicitar reformas de carácter político y civil, como el sufragio universal y la ley del divorcio. La obtención del sufragio universal fue un gran logro para las sufragistas, pero un pequeño paso para el resto de las feministas. Para algunas mujeres, la posibilidad de participar en los comicios y de integrar los partidos políticos

\footnotetext{
${ }^{21}$ Varios artículos y referencias periodísticas al asociacionismo asistencial y filantrópico en PENICHE, A. Cuba es una fábrica de tuberculosis. Bohemia, v. 37, n. 26, 1 julio 1945, p. 25, GARCÍA OCHOA, M. ¡Parasitismo y tuberculosis!. Bohemia, v. 40, n. 40, 3 octubre de 1948, p. 6-7, donde pueden verse 27 hombres y 9 mujeres al frente de la campaña, pero ninguno de ellos es afrocubano, DEL PRADO ARMAND, P Las mujeres hablan ¿Una campaña por la decencia debe limitarse a las manifestaciones artísticas o preocuparse por otros aspectos más fundamentales de la vida nacional?, Bohemia, v. 45, n. 29, 19 julio 1953, p. 64-65, S.A. Cocktail a la prensa, Diario de la Marina, La Habana, 6 enero 1957, D16, S. A. Reparto de juguetes en Guanabo. Diario de la Marina, La Habana, 16 enero 1957, p. 10a , S.A., "Cruz Blanca de la Paz", Diario de la Marina, 19 enero 1957, p. 17a, ARROYO, A., Labor de la Liga antituberculosa del Sanatorio "La Esperanza" conjuntamente con el servicio social y el comité de Damas Católicas, Diario de la Marina, La Habana, 26 de enero de 1957, 29 B., S.A., En junta celebrada ayer se tomaron acuerdos sobre el Baile de la Liga contra la Ceguera. Diario de la Marina, La Habana, 6 de febrero de 1957, p. 13 A, UNIVERSITY OF MIAMI, Cuban Heritage Collection. Fulgencio Batista Zaldívar Collection, Caja 145, Carpeta 36 con fotografías de Martha Fernández colaborando junto a la Liga Contra el Cáncer y HOLBROOK, J. Catholic student movements in Latin America: Cuba and Brazil, 1920s to 1960s, Tesis Doctoral - Florida International University, Miami, 2013, p. 91-99.
}

\section{GANPHLAC}

Revista Eletrônica da ANPHLAC, ISSN 1679-1061, №. 20, p. 141-172, Jan/Jun., 2016. 
eran medidas necesarias pero insuficientes. Al fin y al cabo, la falta de leyes que desarrollasen la constitución de 1940 provocó la inoperatividad de parte de las instituciones que tenían por objetivo llevar a la práctica el nuevo marco legal. En cualquier caso, el reducido número de mujeres en el parlamento y el senado no posibilitó alterar su situación, pues las propuestas relativas a las mujeres fueron muy escasas y recibieron apoyo de forma excepcional, al menos hasta que en 1950 se aprobó la reforma del Código Civil. Por otro lado, ni las instituciones del poder, ni las primeras agrupaciones sufragistas se preocuparon excesivamente por la situación de las mujeres afrodescendientes. El pasado esclavista, la guerra contra el PIC y la perpetuación de prejuicios raciales las mantuvo al margen de la política hasta los años treinta. Su activismo social estaba enfocado al recreo, el ocio y el asistencialismo mutuo que procuraban formación y entretenimiento a personas negras y mestizas. Por su parte, el hecho de que algunas de estas asociaciones afrodescendientes tratasen de abolir sus secciones femeninas demuestra también la existencia de prejuicios de género dentro de estos sectores sociales. Tanto el III Congreso Nacional de Mujeres, de 1939, como las asociaciones comunistas, entre las que cabe destacar la Federación Democrática de Mujeres Cubanas, contribuyeron a visibilizar el problema de las mujeres afrocubanas en los años cuarenta, pero sin llegar a conseguir el suficiente apoyo para implementar grandes reformas legislativas en su favor.

La segunda ola del feminismo no surgió en Estados Unidos hasta los años sesenta y en el resto de Latinoamérica hasta algunos años más tarde. Sin embargo, los antecedentes de este cambio de paradigma continental ya pueden rastrearse en el activismo social y político de las mujeres cubanas durante la República. Entre 1902 y 1959, estas mujeres exigieron un mayor compromiso por parte de las instituciones mediante la petición de reformas legislativas, y consiguieron mayor reconocimiento social a través de sus acciones y proclamas. Las mujeres aumentaron su presencia en la Universidad, pero seguían matriculándose en las mismas carreras y mayoritariamente siguieron trabajando en el servicio doméstico, la alimentación, la educación y el entorno sanitario. Sin embargo, la II Guerra Mundial y el incremento del asociacionismo cívico femenino en los años cuarenta empujaron a un mayor número de mujeres a enrolarse en proyectos y actividades públicas más allá del ámbito laboral o del entorno privado del hogar, lo que en sí mismo supuso un desafío a los roles tradicionales que se le presumían. Su implicación en la democratización del sistema político por medio de campañas contra la pobreza o en favor de la paz, tomando parte en la financiación de las escuelas y el

\section{GANPHLAC}

Revista Eletrônica da ANPHLAC, ISSN 1679-1061, №. 20, p. 141-172, Jan/Jun., 2016.

http://revista.anphlac.org.br 
mantenimiento de los hospitales, fue generando entre las mujeres una mayor conciencia de Estado y reforzó su sentimiento nacionalista. Podría afirmarse que, por esta razón, parte de las mujeres pasaron a engrosar la oposición contra Fulgencio Batista tras el alzamiento militar que en 1952 lideró contra la constitución vigente. De esta forma, la acción política y el activismo social de las mujeres cubanas durante la República deben ser entendidos como parte de un triple proceso de emancipación femenina, democratización de las instituciones estatales y definición de la nacionalidad cubana.

\section{Referencias bibliográficas}

ACCIÓN CÍVICA CIUDADANA. Actividades de las Damas de Acción Cívica Cubana. Batalla. Miami, 7 de julio de 1957

ALIANZA NACIONAL FEMINISTA. XX aniversario de la Alianza Nacional Feminista. La Habana: 1948. Visto en Women's Movement in Cuba, 1898-1958: The Stoner Collection on Cuban Feminism.

American women's unit in Cuba reports arrival of all goods sent to Britain. The Christian Science Monitor, 4 Octubre 1941, p. 3.

ANDERSON, Marjorie. ¿Carrera o matrimonio?. Vanidades, v. 8, n. 18, 2 octubre 1944, p. 22 y 25.

ARCHIVO NACIONAL DE CUBA. Fondo de Asociaciones. Legajo 157, expediente 3187.

ARCHIVO NACIONAL DE CUBA. Fondo de Asociaciones. Legajo 158, expediente 2805.

ARCHIVO NACIONAL DE CUBA. Fondo de Asociaciones. Legajo 178, expediente 3643.

ARCHIVO NACIONAL DE CUBA. Fondo de Asociaciones. Legajo 178, expediente 3610 y http://www.guide2womenleaders.com/Cuba.htm

ARCHIVO NACIONAL DE CUBA. Fondo de Asociaciones. Legajo 193, expediente 4259.

ARCHIVO NACIONAL DE CUBA. Registro de Asociaciones. Legajo 215, expediente 5233, Unión femenina del Partido Demócrata,

\section{GANPHLAC}

Revista Eletrônica da ANPHLAC, ISSN 1679-1061, N. 20, p. 141-172, Jan/Jun., 2016. 
ARCHIVO NACIONAL DE CUBA. Registro de Asociaciones. Legajo 256, expediente 6971, Unión de Mujeres Socialistas Democráticas y

ARCHIVO NACIONAL DE CUBA. Registro de Asociaciones. Legajo 348, expediente 10337, Club de mujeres Auténticas, p. 1-10,

ARROYO, A. Labor de la Liga antituberculosa del Sanatorio "La Esperanza" conjuntamente con el servicio social y el comité de Damas Católicas, Diario de la Marina, La Habana, 26 de enero de 1957, 29 B.,

ARVEY, Sarah R. Making the inmoral moral: consensual unions and birth status in Cuban Law and Everyday Practice, 1940-1958. Hispanic American Historical Review. Durham, v. 90, 2010, p. 627-659,

BARRITEAU, Eudine. Theorizing Gender Systems and the Project of Modernity in the Twentieth-Century Caribbean. Feminist Review, n. 59, p. 186-210, verano, 1998.

BROCK, Lisa y CASTAÑEDA FUENTES, Digna. Between race and empire: AfricanAmericans and Cubans before the Cuban revolution. Philadelphia: Temple University Press, 1998, p. 33-48.

BRONFMAN, Alejandra. La barbarie y sus descontentos: raza y civilización. 1912-1919, Temas, n. 24-25, p. 23-33, 2001.

CASADO FERNÁNDEZ, Ana. Cuerpos (h)errados: mujer y prisión en la narrativa cubana contemporánea. Dicenda. Cuadernos de Filología Hispánica, v. 30, n. especial, p. 195-205, 2012.

CASTANEDA FUERTES, Digna. Between race and empire. African-Americans and Cubans before the Cuban revolution, Philadelphia: Temple University Press, 1998.

CASTILLO BUENO, María de los Reyes y RUBIERA CASTILLO, Daisy. Reyita: testimonio de una negra cubana nonagenaria. La Habana: Ediciones Verde Olivo, 2000

CASTRO PORTA, Carmen. La lección del maestro. La Habana: Oficina de Asuntos Históricos del Consejo de Estado, 2010.

CHASE, Michelle. Revolution within revolution. Women and Gender politics in Cuba, 19521962. Chapel Hill: University of North Carolina, 2015.

CHASE, Michelle. Women's Organizations and the Politics of Gender in Cuba's Urban Insurrection (1952-1958). Bulletin of Latin American History. v. 29, n. 4, 2010.

CHEASLEY, C. W. La mujer de hoy y de mañana. Vanidades, 1 febrero 1945, p. 24, 38 y 39.

CLUB FEMENINO DE CUBA. Nuestra Labor. La mujer moderna. La Habana, noviembre 1925, p. 34-35.

\section{GANPHLAC}

Revista Eletrônica da ANPHLAC, ISSN 1679-1061, ํo. 20, p. 141-172, Jan/Jun., 2016.

http://revista.anphlac.org.br 
Cocktail a la prensa, Diario de la Marina, La Habana, 6 enero 1957, D16.

COFFIGNY, Olga, Mujeres parlamentarias cubanas (1936-1958). Temas, La Habana, n. 22, p. 185-197, jul./sept., 2008.

Cruz Blanca de la Paz. Diario de la Marina, 19 enero 1957, p. $17^{\mathrm{a}}$.

CRUZ MARTÍNEZ, Dania de la. María Luisa Dolz. Documentos para el estudio de su labor pedagógica y social. La Habana: Editorial Academia, 1990.

CRUZ-TAURA, Graciella. Women's rights and the Cuban Constitution of 1940. Cuban Studies, v. 91, n. 1, 133-136, 1994.

CUBA, Constitución de la República de Cuba, 1901, artículo 38. Disponible en http://biblio.juridicas.unam.mx/libros/5/2138/7.pdf.

CUBA. Constitución de 1940. La Habana: Imprenta P. Fernández, 1940.

CUBA. Diario de Sesiones de la Convención Constituyente de la Isla de Cuba, La Habana: 1901. Biblioteca de la Universidad de La Habana (BUH), pp. 283-284 y

Cuban aid to the Allies. The Times, 11 January 1944, p. 5 y

DAVIES, Catherine. National feminism in Cuba: the elaboration of a Counter-Discourse, 19001935. The modern language review, v. 91, n. 1, p. 107-123, 1996

DAVILA, Iris. Pepilla la de Juan. Mujeres, n. 12, p. 10-12, 1976,

DE LOS SANTOS, Asela, ESPÍN, Vilma y ÁLVAREZ MOLA, Marta. Contra todo obstáculo. La Habana: Editorial Verde Olivo, 2011,

DEL PORTAL, Herminia. Las trabajadoras sociales en Cuba. Bohemia. 26 de marzo de 1950, p. 58-60 y 112.

DEL PRADO ARMAND, Pura del. Las mujeres hablan ¿Una campaña por la decencia debe limitarse a las manifestaciones artísticas o preocuparse por otros aspectos más fundamentales de la vida nacional?, Bohemia, v. 45, n. 29, 19 julio 1953, p. 64-65,

DESVERNINE REED, Sara. Havana: a study in interiors, identities and ideologies. 357 p., Tesis Doctoral - University of Delaware, 2013.

ECHEVERRÍA, Ángeles. Día internacional de la Mujer. Nunca dejó de celebrarse. Mujeres, La Habana, n. 3, p. 16-17, 1977.

En junta celebrada ayer se tomaron acuerdos sobre el Baile de la Liga contra la Ceguera. Diario de la Marina, La Habana, 6 de febrero de 1957, p. 13 A,

\section{GANPHLAC}

Revista Eletrônica da ANPHLAC, ISSN 1679-1061, No. 20, p. 141-172, Jan/Jun., 2016. 
FEDERACIÓN NACIONAL DE ASOCIACIONES FEMENINAS, Memoria Del Primer Congreso Nacional De Mujeres: April 1 a 7 De 1923. 1923 y Memoria Del Segundo Congreso Nacional De Mujeres. Abril 12 a 18 de 1925.

FINKELMAN, M. ¿Hacia dónde van las mujeres?. Bohemia, 9 octubre 1949, p. 10-12 y 223.

FRANCO, Stella Maris Scatena y PRADO, Maria Ligia Coelho. A participação das mulheres na independência da Nova Granada: gênero e construção de memórias nacionais. In: PAMPLONA, Marco A., MÄDER, Maria Elisa (Org.). Revoluções de independências e nacionalismos nas Américas: Nova Granada, Venezuela e Cuba. São Paulo: Paz e Terra, 2009, v. 3, p. 171-236.

GARCÍA BELAUNDE, Domingo. El tribunal de Garantías Constitucionales y sociales de Cuba (1940-1952). Boletín Mexicano de Derecho Comparado, v. 37, p. 283-312, 2004.

GARCÍA OCHOA, Martha. ¡Parasitismo y tuberculosis!. Bohemia, v. 40, n. 40, 3 octubre de 1948, p. 6-7.

GARCÍA OLIVEIRA, Julio. Contra Batista. La Habana: Editorial de Ciencias Sociales, 2006.

GARCÍA PÉREZ, Gladys Marel. Mujer y revolución: Una perspectiva desde la insurgencia cubana (1952-1959). RUTH, n. 3, p. 63-66, 2009.

GARCÍA TUDURÍ DE GOYA, Mercedes. La crisis de la familia. Bohemia, v. 40, n. 37, 5 septiembre 1948, p. 46-47.

GARCÍA-PÉREZ, Gladys Marel. Género, historia y sociología. Cuba. Siglo XX: mujer y revolución. Algunos apuntes sobre estudios de casos y familias a partir de la perspectiva de la Nación y la emigración, Santiago, n. 86, p. 114, 1999.

GÓMEZ CARBONELL, María. La mujer cubana y la guerra. Vanidades, v. 9. n. 17, 1 septiembre 1942, p. 14.

GONZÁLEZ CABRERA, Heidy. Cincuentenario de una rebeldía: El soviet de Mabay. Mujeres, La Habana, n. 8, agosto 1983, p. 15-17.

GONZÁLEZ, Edelmira. Estampas de la cárcel. La Habana: s.e., 1950, p. 83-93, in: Women's Movement in Cuba, 1898-1958: The Stoner Collection on Cuban Feminism.

GUERRERO, Maria Luisa. Elena Mederos, una mujer con perfil para la historia. Washington: Miami Universal, 1991.

GURIDY, Frank A. From solidarity to cross-Fertilization: Afro-Cuban / African American interaction during the 1930s and 1940s. Radical History Review, n. 87, p. 19-48, 2003.

\section{CANPHLAC}

Revista Eletrônica da ANPHLAC, ISSN 1679-1061, No. 20, p. 141-172, Jan/Jun., 2016.

http://revista.anphlac.org.br 
HELG, Aline. Políticas raciales en Cuba después de la independencia: Represión de la cultura negra y el mito de la igualdad racial. América Negra, n. 11, p. 63-83, 1996.

HERRERA VALDÉS, Aleida y COFFIGNY LEONARD, Olga. La temática femenina en el fondo Congreso de la República de Cuba, Boletín del Archivo Nacional de la República de Cuba. 1902-2002. Cien años divulgando historia. La Habana: Archivo Nacional de Cuba, 2001-2002, n. 13-14, pp. 139-149. Disponible en https://archive.org/stream/boletindelarchiv00drab/boletindelarchiv00drab_djvu.txt].

HIDALGO, Leyma. El Club de Atenas y la cuestión racial: boletín y revista de 1917 a 1931. Iberoamericana Global, Jerusalem, v.2, p. 30-45, 2012.

HOLBROOK, Joseph. Catholic student movements in Latin America: Cuba and Brazil, 1920s to 1960s, Tesis Doctoral - Florida International University, Miami, 2013, p. 91-99.

IBARRA Jorge. Cuba: 1898-1958. Estructura y procesos sociales. La Habana: Editorial Ciencias Sociales, 1995, p. 162.

IBARRA, Jorge. Cuba. 1898-1958. Estructura y procesos sociales. Madrid: Editorial de Ciencias sociales 1995, p. 174-180.

INTERNATIONAL CONFEDERATION OF FREE TRADE UNIONS. Preparatory committee on questions dealing with women workers. Bruselas, 14 Febrero 1956. Disponible en http://wasi.alexanderstreet.com.ezp-prod1.hul.harvard.edu/view/1688626 (20 noviembre 2015).

JOHNG, Elena M. de. Feminismo y periodismo en la Cuba republicana: Ofelia Rodríguez Acosta y la campaña feminista de "Bohemia" (1930-1932). Confluencia, Colorado, v. 11, n. 1, p. 3-12, otoño, 1995.

KEOSHA, Takkara. Constructing afro-cuban womanhood: race, gender and citizenship in republican era Cuba, 1902-1958. 2011, 329 p. Tesis Doctoral - University of Texas.

KLOUZAL, Linda. Women and rebel communities in the Cuban insurgent movement, 19521959. Youngstown-New York: Cambria, 2008.

KRADITOR, Aileen S. The ideas of the woman suffrage movement 1890-1920. New York: Norton, 1981, p. 123-261.

KROLOKKE, Charlotte y SCOTT SORENSEN, Anne Scott. Gender communication. Theories and Analyses. Thousand Oaks: SAGE Publications, 2005, p. 1-7.

La odisea de una generación. Del presidio político al poder. Bohemia. La Habana, 9 octubre 1949, p. 28-30.

LAMAR, Hortensia. Lucha contra el alcoholismo. La mujer moderna. La Habana, febrero 1926, p. 27-28.

\section{GANPHLAC}

Revista Eletrônica da ANPHLAC, ISSN 1679-1061, No. 20, p. 141-172, Jan/Jun., 2016. 
LAMAR, Hortensia. Lucha contra la prostitución y la trata de blancas. Revista Bimestre Cubana, n. 18, mar./abr., 1923.

LAMAR, Hortensia. Problemas nacionales. La mujer moderna. La Habana, noviembre 1925, p. 25-27.

LATIN AMERICAN STUDIES ASSOCIATION CONFERENCE, 17-18 Octubre 1981.

LYNETTE LOGAN, Enid. Each sheep with its mate: marking race and legitimacy in Cuban catholic parish archives, 1890-1940. New West Indian Guide, v. 84, n. 1, p. 5-39, 2010.

MACKINNON, Catherine A. Feminism: Marxism, Method and the State: An agenda for theory. Signs, Chicago, v. 8, n. 32, p. 635-658, verano, 1983.

MARQUINA, Rafael. Hacer el bien y saber hacerlo. Bohemia, v. 44, n. 43, 26 octubre 1952, p. 64-66.

MARTÍN, Daisy. Enfermeras del segundo frente. Mujeres. n. 11, p. 48-49, 1976.

MARTÍNEZ MALO, Aldo. Dulce María Loynaz: memorias de una poetisa. Pinar del Río: Hermanos Loynaz, 2010.

MARTÍNEZ SIERRA, Gregorio. ¿Qué deben estudiar las mujeres?. Vanidades, n. 12, 1 junio 1945, v. 15, n. 12, p. 13.

MEDEROS, Elena. In defense of Motherhood: Divorce Law in Cuba during the Early Republic. Disponibles en University of Miami, Cuban Heritage Collection, Fondo Elena Mederos, Caja 2.

MEDEROS, Elena. In defense of Motherhood: Divorce law in Cuban During the Early Republic. Disponible en University of Miami, Cuban Heritage Collection.

MEDEROS, Elena. La posición de la mujer en Cuba. S.f., S.e., 1952-1953, p. 9 y 10.

MENÉNDEZ, Nina R. No woman is an island: Cuban women's fiction in the 1920s and 30. 168 p., Tesis Doctoral - Stanford University, 1993.

MERIÑO FUENTES, Mari Ángeles. Una vuelta necesaria a mayo de 1912. La Habana: Editorial de Ciencias Sociales, 2006, p. 116.

MILLÁS, Roland, Cuban divorce law. University of Miami Law Review, v. 3, n. 22, p. 270274, 1949.

MONTEJO ARRECHEA, Carmen. Minerva. A magazine for women (and Men) of color. In:

\section{GANPHLAC}

Revista Eletrônica da ANPHLAC, ISSN 1679-1061, №. 20, p. 141-172, Jan/Jun., 2016.

http://revista.anphlac.org.br 
MUJERES OPOSICIONISTAS UNIDAS. Propósitos. Boletín informativo. Julio de 1958. Disponible en Fondo de Prensa Clandestina 1952-1958, Biblioteca Nacional de Cuba.

MULHARE, Mirta De la Torre. Sexual ideology in pre-Castro Cuba: a cultural analysis.1969. 290 p. Tesis Doctoral - Pittsburgh University, 1969,

NARANJO OROVIO Consuelo y GARCÍA GONZÁLEZ, Armando. Inmigraciones e "higiene racial” en Cuba, 1900-1940. En CAYUELA J.G. (coord.). Un Siglo de España: Centenario 1898-1998. Cuenca: Universidad de Castilla-La Mancha/Cortes de Castilla-La Mancha, p. 437449, 1998.

NARANJO OROVIO, Consuelo y GARCÍA GONZALEZ, Armando Medicina y racismo en Cuba. La ciencia ante la inmigración canaria en el siglo XX. La Laguna-Tenerife: Casa de la Cultura Popular Canaria, 1996.

NARANJO OROVIO, Consuelo y PUIG-SAMPER MULERO, Miguel Ángel. Delincuencia y racismo en Cuba: Israel Castellanos versus Fernando Ortiz. En ORTIZ, Carmen y HUERTAS, Rafael (eds.). Ciencia y fascismo. Madrid-Aranjuez: Ediciones Doce Calles, 1998, p. 11-21.

NARANJO OROVIO, Consuelo, Cuba, otro escenario de lucha: la guerra civil y el exilio republicano español. Madrid: CSIC, 1988, p. 89-94.

NARANJO OROVIO, Consuelo, De la esclavitud a la criminalización de un grupo: la población de color en Cuba. Nuevo Mundo, Mundos Nuevos, 18 marzo 2006. Disponible en http://nuevomundo.revues.org/2019.

NARANJO OROVIO, Consuelo. La historia se forja en el campo. Nación y cultura cubana en el siglo XX. Historia Social, n. 40, p. 165-172, 2001.

NÚÑEZ, Jorge. Modernización y cambio cultural en La Habana (1915-1920). 368 p., Tesis Doctoral - Universidad Pompeu Fabra, 2011, pp. 71-249.

ORTIZ-LOYOLA, Brenda. En busca de la solidaridad: feminismo y nación en el Caribe hispano 1880-1940. 277 p., Tesis Doctoral - University of California, 2013.

PAGÉS, Julio César. En busca de un espacio: historia de mujeres en Cuba. Madrid: Pinos Nuevos, 2003

PAGÉS, Julio César. La lucha por el sufragio femenino en Cuba. Siglos XIX y XX. Tesis Doctoral - Universidad de La Habana, La Habana, 2000.

PAGÉS, Julio César. La República femenina: Organizaciones revolucionarias de Mujeres, 1952-1958. Tesis de Maestría - Universidad de La Habana, La Habana, 1991.

PENICHE, Antonio. Cuba es una fábrica de tuberculosis. Bohemia, v. 37, n. 26, 1 julio 1945, p. 25.

\section{GANPHLAC}

Revista Eletrônica da ANPHLAC, ISSN 1679-1061, No. 20, p. 141-172, Jan/Jun., 2016.

http://revista.anphlac.org.br 
PÉREZ GARZÓN, Juan Sisinio. Feminismo. Madrid: Catarata, 2011, p. 111-140.

PIGNOT, Elsa. El asociacionismo negro en Cuba: una vía de integración en la sociedad republicana (1920-1960), Revista de Indias, vol. 70, n. 250, p. 837-862.

PRADO, Maria Ligia C. A participação das mulheres nas lutas pela independência política da América Latina. Em: PRADO, Maria Ligia C. América Latina no século XIX. Tramas, telas e textos. São Paulo: Edusp, 1999. pp. 29-73.

RAMÍREZ CHICHARRO, Manuel. Desde la clandestinidad. Una historia oral de las mujeres cubanas que lucharon contra Batista (1952-1959). Ibero-Americana Pragensia. Supplementum, n. 44, 2016.

RAMÍREZ CHICHARRO, Manuel. Doblemente sometidas: las "mujeres de color" en la República de Cuba (1902-1959). Revista de Indias. v. 74, n. 262, p. 783-828.

Recibimiento de la primera dama. Bohemia, v. 45, n. 49, 6 diciembre 1953, p. 81.

Reparto de juguetes en Guanabo. Diario de la Marina, La Habana, 16 enero 1957, p. 10A.

REPÚBLICA DE CUBA. Censo de 1943 de la República de Cuba. La Habana: Fernández y Cía, 1945.

REPÚBLICA DE CUBA. Censo de la República de Cuba, año de 1919. La Habana: Maza, Arroyo y Caso, 1921.

REPÚBLICA DE CUBA. Censo de Población de la República de Cuba 1907 bajo la administración provisional de los EEUU. Washington: Oficina del Censo de los EEUU, 1908.

REPÚBLICA DE CUBA. Censo del año de 1931, resumen. La Habana: S.e. 1931.

REPÚBLICA DE CUBA. Censos de población, viviendas y electoral, 1953. La Habana: Dirección General del Censo, 1953.

REXACH, Rosario. El Lyceum de la Habana como institución cultural. AIH, Actas IX, 1986. Disponible en http://cvc.cervantes.es/literatura/aih/pdf/09/aih_09_2_077.pdf.

REYNOLDS, Geneviere. Advances of women in Cuba conflict with old traditions. The Washington Post, Washington, 3 octubre 1943, p. S5.

RIERA, Mario. 52 años de política. Oriente. 1898-1952. La Habana: s.e., 1953, RIERA, M. Cuba política. 1899-1955. La Habana: Impresora Modelo, 1955.

RIVERA MARTÍNEZ, Mildred. El modernismo en el Caribe insular hispano, 1898-1915. 289 p., Tesis Doctoral - Standford University, 1992, p. 135-156.

\section{GANPHLAC}

Revista Eletrônica da ANPHLAC, ISSN 1679-1061, No. 20, p. 141-172, Jan/Jun., 2016.

http://revista.anphlac.org.br 
RODRÍGUEZ VILLAMIL, Silvia y SAPRIZA, Graciela. El voto femenino en el Uruguay: ¿conquista o concesión?. Montevideo: GRECMU, 1984.

SECCIÓN FEMENINA DE ACCIÓN CÍVICA CUBANA. Para rendir tributo ninguna voz es débil. Batalla, Miami, 4 de agosto 1957. Haydée de Santamaría y Dysis Guira fueron dos de las activistas del MR26 y del DR más activas en el extranjero.

SOLAR CABRALES, Frank Josué. Entre el golpe y el asalto: la Universidad de La Habana antes del 26 de julio de 1953, Santiago, n. 133, p. 129-139, 2013.

SORAVILLA, Lesbia. Cómo vive una empleada pública. Vanidades, v. 8, n. 2, 15 noviembre 1941, p. 48.

SOTO, Lionel. La revolución del 33. La Habana: Editorial de Ciencias Sociales, 1977, t. III.

SOUSA E. SANTOS, Dina Sebastiana de. Jineterismo in Havana: Narrating the Daily Struggles of Afro-Cuban Jineteras. Tesis Doctoral - University of Southampton, 2007, p. 55-56 y 94100.

STONNER, Katherine L. De la casa a la calle. El movimiento cubano de la mujer en favor de la reforma legal (1898-1940). La Habana: Colibrí, 2003.

TORRES-ELERS, Damaris A. Santiagueras en el alzamiento de 1912: ¿leyenda o realidad?, Santiago, n. 133, abr. 2013, p. 116-128.

TORRIENTE BRAU, Pablo. de la, Testimonios y paisajes. La Habana: Centro Cultural Pablo de la Torriente Brau, 2001, p. 108.

UNIÓN DE MUJERES ASOCIADAS. Homenaje nacional de las Asociaciones Femeninas al honorable presidente de la República, Carlos Prío Socarrás en el Vedado Tennis Club. 2 de junio de 1949. Disponible en Women's Movement in Cuba, 1898-1958: The Stoner Collection on Cuban Feminism.

WATERS, Mary-Alice. Marianas en combate: Teté Puebla \& el Pelotón Femenino Mariana Grajales en la guerra revolucionaria cubana, 1956-1958. New York: Pathfinder, 2003.

\section{GANPHLAC}

Revista Eletrônica da ANPHLAC, ISSN 1679-1061, ํo. 20, p. 141-172, Jan/Jun., 2016.

http://revista.anphlac.org.br 